\title{
High Temperature Stability of Dissimilar Metal Joints in Fission Surface Power Systems
}

\author{
Ivan E. Locci ${ }^{1}$, James A. Nesbitt ${ }^{2}$, Frank J. Ritzert ${ }^{2}$, and Cheryl L. Bowman ${ }^{2}$ \\ ${ }^{I}$ University of Toledo at NASA Glenn Research Center at Lewis Field, Cleveland, OH 44135 USA \\ ${ }^{2}$ NASA Glenn Research Center at Lewis Field, Cleveland, OH 44135 USA \\ ${ }^{J}$ (216) 433-5009, ivan.elocei@nasa.gov
}

\begin{abstract}
Future generations of power systems for spacecraft and lupar surface systens will likely require a strong dependence on nuclear power. The design of a space nuclear power plant involves integrating together major subsystems with varying material requirements. Refractory alloys are repeatedly considered for major structural components in space power reactor designs because refractory alloys retain their strength at higher temperatures than other classes of metals. The relatively higher mass and lower ductility of the refractory alloys make them less attractive for lower temperature subsystems in the power plant such as the power conversion system. The power conversion system would consist more likely of intermediate temperature Ni-based superalloys. One of many unanswered questions about the use of refractory alloys in a space power plant is how to transition from the use of the structural refractory alloy to more traditional structural alloys. Because deleterious phases can form when complex alloys are joined and operated at elevated temperatures, dissimilar material diffusion analyses of refractory alloys and superalloys are needed to inform designers about options of joint temperature and operational lifetime. Combinations of four superalloys and six refractory alloys were bonded and annealed at $1150 \mathrm{~K}$ and $1300 \mathrm{~K}$ to examine diffusional interactions in this study. Joints formed through hot pressing and hot isostatic pressing were compared. Results on newer alloys compared favorably to historical data. Diffisional stability is promising for some combinations of Mo-Re alloys and superalloys at $1150 \mathrm{~K}$, but it appears that lower joint temperatures would be required for other refractory alloy couples.
\end{abstract}

Keywords: Superalloys, refractory alloys, joining, diffusion bond, microstructure, interlayers, interface PACS: 66.10.Cb, 66.30.-h, 66.30.Fq, 66.30.Lw, 66.30.Ny, 68.35.Fx

\section{INTRODUCTION}

Preliminary designs for the Jupiter Icy Moons Orbiter (JMO) mission included a fission heat source with a high thermal output (Mason, 2005). Candidate designs for the heat source typically included refractory metal alloys in the high temperature core and a transition to more traditional high temperature superalloys for the balance of the plant (Zinkle and Wiffen, 2004). In addition to having a data base of alloy properties for potential refractory metals and superalloys, power plant designers needed input on the strength and stability of candidate dissimilar metal joints. The stability of refractory metals o Ni-base alloys was considered a significant challenge for a high power reactor system assembly since these joints will likely be exposed for thousands of hours at high temperatures. There are typically three concerns associated with joining dissimilar alloys: (1) formation of low melting phases, (2) formation and growth of deleterious (e.g., brittle) phases, and/or (3) formation of "Kirkendall" porosity (porosity resulting from diffusional transport). Low melting temperature phase formation is typically a problem associated with initial bonding and can often be avoided by the selection of appropriate alloys. However, diffusional transport between dissimilar metals cannot be avoided if the components dwell at high temperatures.

A thorough evaluation of certain combinations of either nickel-based alloys or iron-based alloys with niobium- and tantalum-based refractory alloys has been previously reported (Buckman and Goodspeed, 1969). This study employed explosive bonding as the joining technique and annealing temperatures from $1033 \mathrm{~K}$ to $1144 \mathrm{~K}$. The authors noted that the brittle reaction zone grew faster in the nickel-alloy-to-reftactory-alloy joints than the iron- 
alloy-to-refractory-alloy joints. They also concluded that mechanical strength of the joint was adversely affected when the reaction zone reached a critical size of $12 \mu \mathrm{m}$. The current work sought to build upon these previous results by considering combinations of modern nickel-based superalloys and leading candidate refractory alloys as well as conducting more detailed analysis of the interfaces afforded by more advanced microscopy techniques. The results presented in this paper are a preliminary study to identify diffusional-interaction issues and aid in downselecting superalloys and refractory alloy candidates for more detailed database generation. This research involved joining various superalloys and refractory alloys at either 1150 or $1300 \mathrm{~K}$ and characterizing the joint microstructure after numerous exposure times. Diffusion bonding was the primary technique used for the present study because it allowed rapid screening of many dissimilar-material joints. Other papers have discussed practical fabrication options for joining these materials (Gould et al., 2006).

\section{MATERIAL SELECTION}

Refractory alloy candidates based on molybdenum (Mo), niobium $(\mathrm{Nb})$, and tantalum $(\mathrm{Ta})$ have been considered for possible reactor construction. One representative alloy from each elemental class was considered in this initial screening. The refractory alloys tested were Mo-47Re (53Mo-47Re), FS-85 (60.2Nb-28Ta-11W-0.8Zr), T111 (90Ta-8W-2Hf) and ASTAR $811 \mathrm{C}(90.3 \mathrm{Ta}-8 \mathrm{~W}-1 \mathrm{Re}-0.7 \mathrm{Hf}-0.025 \mathrm{C})$ as well as pure tantalum. All alloy compositions are in weight percent unless otherwise noted. Nickel-based superalloys are the baseline choice for high temperature, structural components in terrestrial applications. Wrought-processed superalloys have good fabricability and weldability and thus are preferred for static ducting and housing applications. Other alloys tailored to take advantage of fine microstructural features developed through casting can provide increased creep strength in the highest stress configurations. The Ni-base superalloys that were investigated in this study were wrought Inconel® $617(55 \mathrm{Ni}-22 \mathrm{Cr}-12.5 \mathrm{Co}-9 \mathrm{Mo}-1 \mathrm{Al}-0.07 \mathrm{C})$, Haynes ${ }^{\circledR} 230(59.8 \mathrm{Ni}-1.3 \mathrm{Fe}-21.6 \mathrm{Cr}-0.34 \mathrm{Co}-1.5 \mathrm{Mo}-14 \mathrm{~W}-$ $0.3 \mathrm{Al}-0.1 \mathrm{C}-0.5 \mathrm{Mn}-0.4 \mathrm{Si}-0.03 \mathrm{~B})$, MarM247 (59.9Ni-8.3Cr-10Co-10W-3Ta-5.5Al-1Ti-0.7Mo-1.5Hf-0.05Zr-0.14C) and Hastelloyß $\mathrm{X}(46.3 \mathrm{Ni}-21.6 \mathrm{Cr}-18.9 \mathrm{Fe}-8.9 \mathrm{Mo}-1.9 \mathrm{Co}-0.085 \mathrm{C}-0.5 \mathrm{Si}-0.009 \mathrm{Mg}-0.6 \mathrm{Mn}-0.5 \mathrm{~W}-0.3 \mathrm{Al}-0.01 \mathrm{Ti}-0.05 \mathrm{~V}-$ $0.12 \mathrm{Cu}-0.08 \mathrm{Nb}-0.048 \mathrm{~N}-0.0010$ ). Hastelloy $(\mathrm{X})$ represents an older class of wrought superalloys used in heritage space power applications. MarM247 represents a modern alloy tailored for casting, while Inconel $\mathbb{B} 617$ and Haynes ${ }^{\circledR} 230$ are modern wrought alloys that are good candidates for many space power components. In addition to joints formed directly between the refractory alloys and superalloys, selected diffusion couples were formed with thin interlayers of either nickel (Ni) or molybdenum (Mo), but results indicating any benefit are still preliminary. Table 1 lists the diffusion couples that were formed by diffusion bonding as well as subsequent annealing conditions. Details of the bonding procedure, annealing, and subsequent analysis will be discussed in the subsequent sections.

TABLE 1. Alloys, Bonding Conditions and Annealing Conditions Used in this Diffusion Study.

\begin{tabular}{|c|c|c|c|c|c|c|}
\hline \multirow{2}{*}{ Superalloy } & \multirow{2}{*}{ Refractory } & \multicolumn{2}{c|}{ Hot Pressing } & \multicolumn{3}{c|}{ Annealing } \\
& & & \multicolumn{2}{c|}{ (in Argon) } \\
\cline { 3 - 7 } & & Temp. (K) & Time (hrs) & Temp. (K) & \multicolumn{2}{c|}{ Time (hrs) } \\
\hline \multirow{2}{*}{ HA230 } & FS-85 or Mo-47Re & 1300 & 1 & 1300 & 25 & 100 \\
\cline { 2 - 7 } & & 1150 & 4 & 1150 & 100 & 300 \\
\hline HA230 & T111, ASTAR811C or Ta-10W & 1150 & 4 & 1150 & 100 & 300 \\
\hline IN617 & FS-85 or Mo-47Re & 1300 & 1 & 1300 & 25 & 100 \\
\cline { 2 - 7 } & & 1150 & 4 & 1150 & 100 & 300 \\
\hline MM247 & Ta or T111 & 1300 & 1 & 1300 & 100 & \\
\hline MM247/Ni & T111 & 1300 & 1 & 1300 & 100 & \\
\hline HX & Ta or T111 & 1300 & 1 & 1300 & 100 & \\
\hline HX/Ni & T111 & 1300 & 1 & 1300 & 100 & \\
\hline HX/Ni/Mo & Mo-47Re & 1300 & 1 & 1300 & 100 & \\
\hline HA230 & Mo-47Re or T111 & 1150 & 4 & $1050^{*}$ & $1000^{*}$ & $3000^{*}$ \\
\hline
\end{tabular}

* In progress 


\section{PROCEDURE FOR HOT PRESSING DIFFUSION COUPLES}

Joints between the superalloys and refractory alloys were produced by hot pressing small coupons of each material in vacuum for either 4 hours $(1150 \mathrm{~K})$ or 1 hour $(1300 \mathrm{~K})$ with a pressure of $90 \mathrm{MPa}$. The two temperatures were initially selected to guarantee that some solid state bonding would occur. Figure 1 shows an illustration of a dissimilar material stack-up. By stacking the disks, a single hot-press run could form several diffusion couples at once.

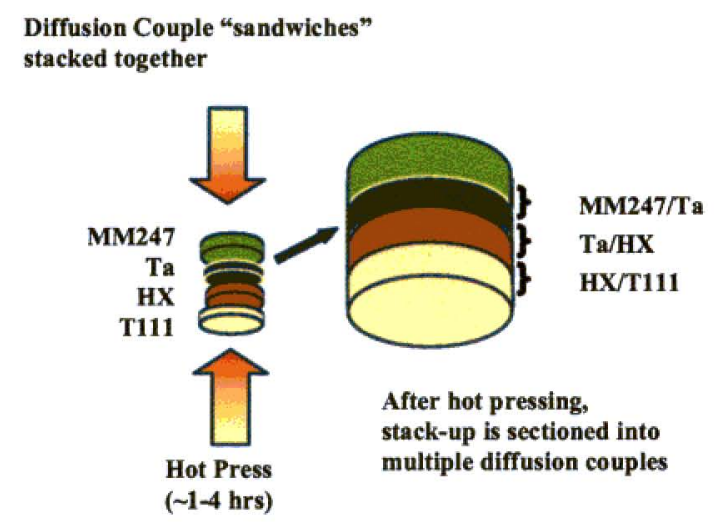

FIGURE 1. Illustration of Hot Pressing Sequence to Produce Multiple, Dissimilar Metal Diffusion Couples.

After this initial bond was formed, the diffusion couple stack was typically sectioned to yield the initial bond conditions. The remainder of the diffusion couple was then subjected to additional annealing in a horizontal tube furnace in an ultra-high-purity Argon atmosphere until the next analysis time indicated in Table 1 . The diffusion couple was again sectioned with one piece for analysis and the remainder again annealed until the final analysis time. After each anneal, the diffusion couples were sectioned, mounted and polished, and the diffusion-affected region of the bond was examined by optical and field emission scanning electron microscopy in the as-polished condition. Some couples were further examined for compositional variations using energy dispersive spectroscopy and microprobe analysis.

\section{RESULTS AND DISCUSSION}

The goal of the research was to survey alloy combinations based on reaction zone thickness and morphological observation. To understand how the interface changes with time and temperature, the first requirement is a sound bond line. Therefore the initial approach of this work was to investigate hot pressing parameters to join a variety of superalloys and refractory alloys. Observations of the bond produced under various hot pressing conditions were used to guide the selection of the threshold temperature to create a sound bond, but not an extensive reaction zone. The first hot pressing processing iteration was done at $1300 \mathrm{~K}\left(1027^{\circ} \mathrm{C}\right)$ to guarantee a good interdiffusion bond, but resulted in very thick reaction zones $(>12 \mu \mathrm{m})$ in most diffusion couples. Figure 2 depicts the interdiffusion reaction zone widths observed in the various superalloy/ refractory couples studied after the one hour hot pressing step and the post anneal treatment of 100 hours. The thickest diffusion zones were associated with combinations of MarM247 and tantalum alloys while the thinnest diffusion zones resulted from combination of HA230 or IN617 with the Mo-47Re refractory alloy. However, all exposures of $100 \mathrm{hrs}$ at $1300 \mathrm{~K}$ resulted in diffusion reaction zones close to or greater than the $12 \mu \mathrm{m}$ critical thickness previously suggested (Buckman and Goodspeed, 1969).

Again, the worst case scenario occurred with the combination of MarM247 and two of the tantalum systems (pure $\mathrm{Ta}$ and T111), where the reaction zone widths reached values greater than $50 \mu \mathrm{m}$ after only 100 hours. The niobium alloy (FS85) also reacted quite severely with either HA230 or IN617 superalloys, reaching diffusion zone widths close to $50 \mu \mathrm{m}$. Figure 3 shows typical complex reaction zones composed of multilayers and multiphases observed in (a) MarM247/Ta and (b) HA230/FS85 diffusion couples. In these severely reacted diffusion couple bonds, longitudinal cracks have developed in continuous refractory enriched layers. 


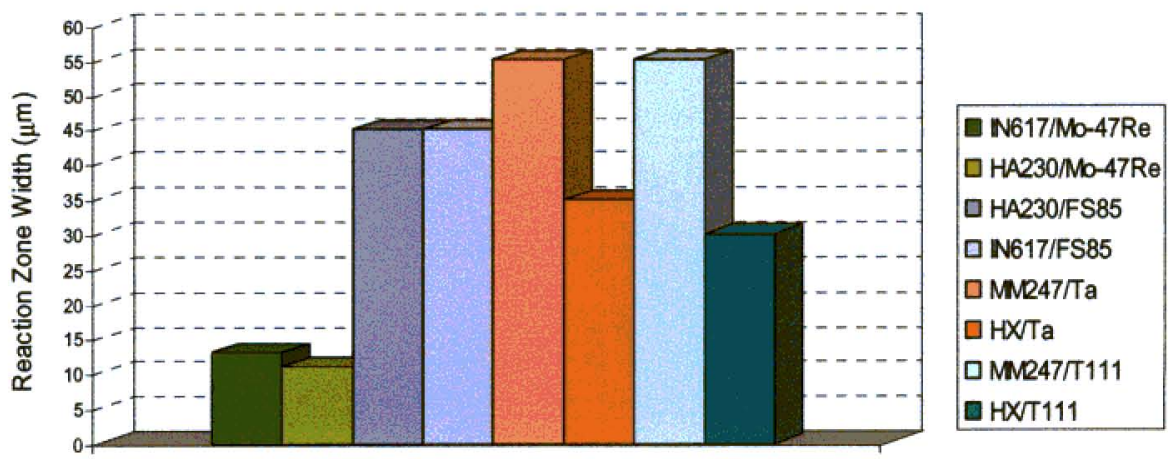

Superalloy/Refractory Combinations

FIGURE 2. Interdiffusion Reaction Zone Width for the Ni-based Superalloy/Refractory Combinations Studied after a 1 Hour Hot Pressing and a 100 Hour Total Exposure at $1300 \mathrm{~K}$.

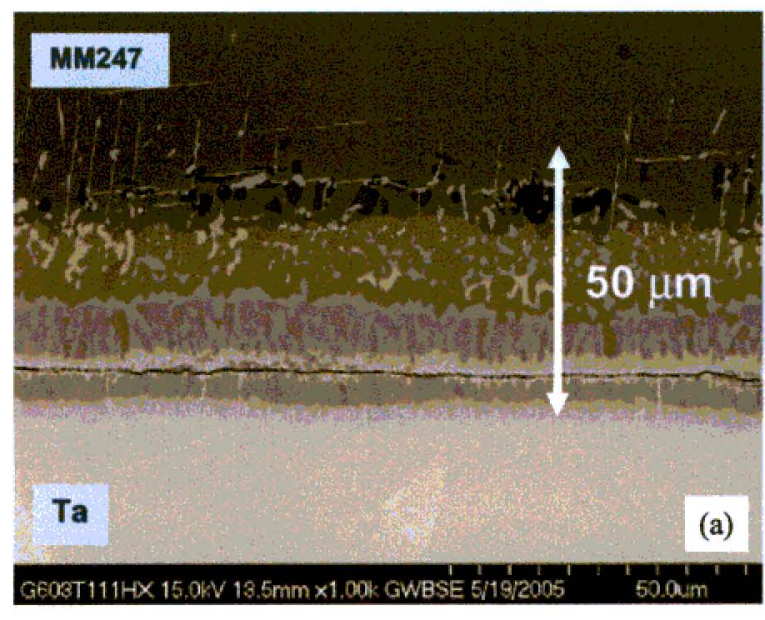

(a) MarM247/Ta Couple

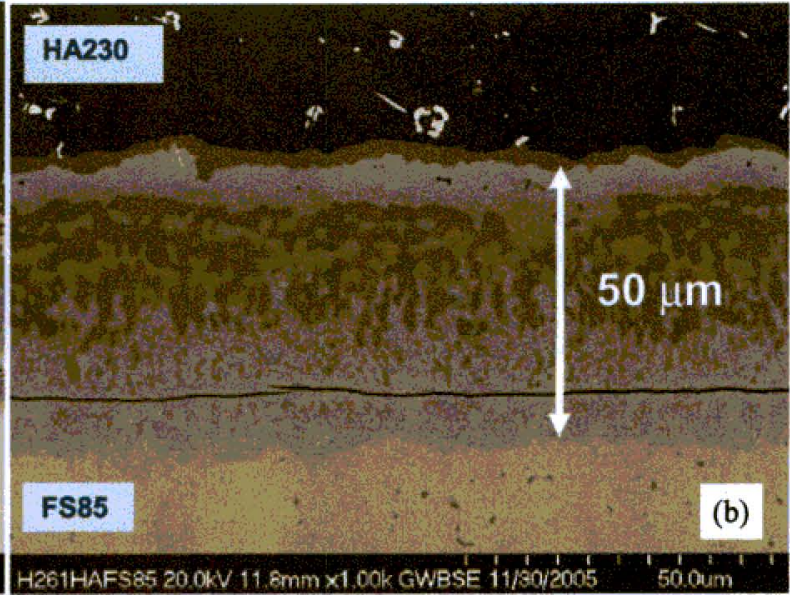

(b) HA230/FS-85 Couple

FIGURE 3. Complex Reaction Zones that Developed after the 1 Hour Hot Pressing Step and the 100 Hour Total Exposure at $1300 \mathrm{~K}$.

Figure 4 compares the evolution of the interdiffusion zone thickness as a function of time for the HA230 and IN617 superalloys with Mo-47Re and FS-85 refractory alloys. It is clear that the Mo-47Re refractory alloy / superalloy combinations had slower diffusion kinetics. Results showed the Mo-47Re reaction zone widths to be up to four times smaller than those associated with Nb-based FS-85. Also, the HA230/Mo-47Re diffusion couples exhibited a slightly reduced reaction zone in comparison to the IN617/Mo-47Re couples.

Figure 5 contrasts the interdiffusion reaction zone width as a function of time for HA230 or IN617 superalloys bonded to Mo-47Re refractory at $1150 \mathrm{~K}$ and $1300 \mathrm{~K}$. Hot pressing at $1150 \mathrm{~K}$ resulted in a $2 \mu \mathrm{m}$ thick diffusion zone, and the anneal exposure up to 300 hours in a 4 to $5 \mu \mathrm{m}$ thick diffusion zone. The microstructures presented in Figure 6 reveal the $3 \mu \mathrm{m}$ diffusion zone that has developed after the $100 \mathrm{~h}$ anneal at $1150 \mathrm{~K}$, while a thicker reaction zone containing a large crack has formed at $1300 \mathrm{~K}$. As summarized in Figure 7, the least reactive of the refractory alloys was again the Mo-47Re, followed by the Ta-based alloys, and then the Nb-based FS85 alloy. It appears that a $1150 \mathrm{~K}$ joint temperature is a more realistic goal for designing a joint with dissimilar metals in a power plant system. Obviously, decreasing the temperature from 1300 to $1150 \mathrm{~K}$ reduced the diffusion kinetics which promotes slower reaction zone growth. However, $1150 \mathrm{~K}$ was still an aggressive condition for the diffusion couples studied. 


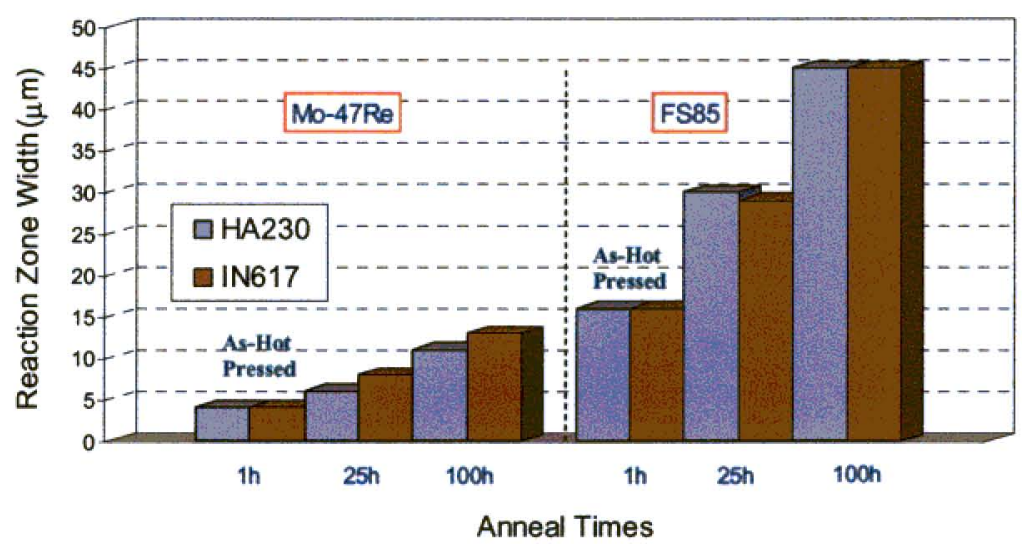

FIGURE 4. Interdiffusion Reaction Zone Width as a Function of Time for various Ni-based Superalloy/Refractory Combinations after Hot Pressing and Anneal at $1300 \mathrm{~K}$.

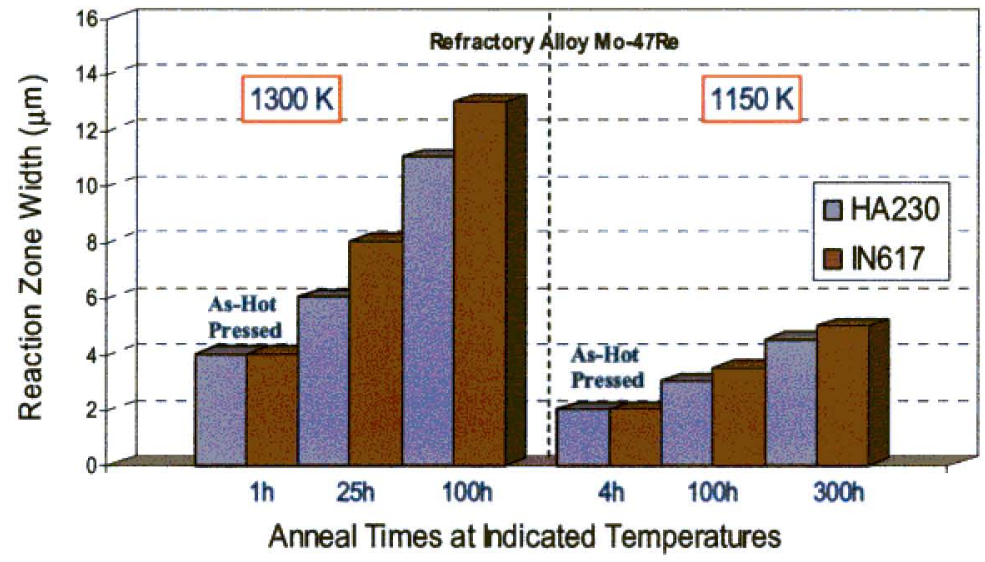

FIGURE 5. Interdiffusion Reaction Zone Width as a Function of Time for two Ni-based Superalloys Bonded to Mo-47Re Alloy Annealed at either 1150 or $1300 \mathrm{~K}$.

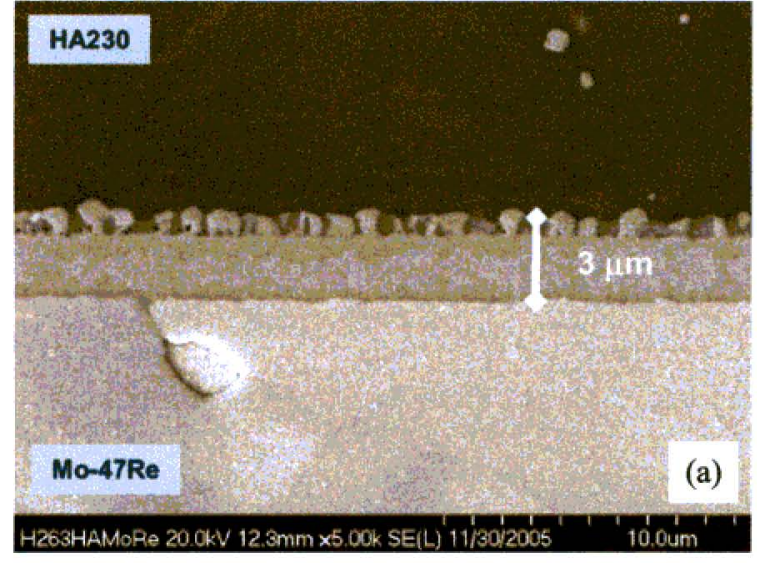

(a) $1150 \mathrm{~K}$

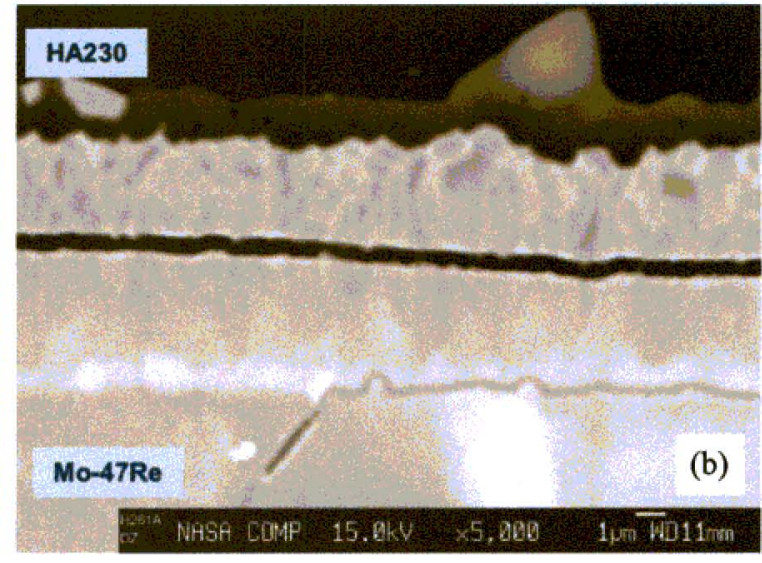

(b) $1300 \mathrm{~K}$

FIGURE 6. FESEM images showing reaction zones that developed at the bond interface of HA230 superalloy and Mo-47Re refractory alloy after a $100 \mathrm{~h}$ anneal at two temperatures. 


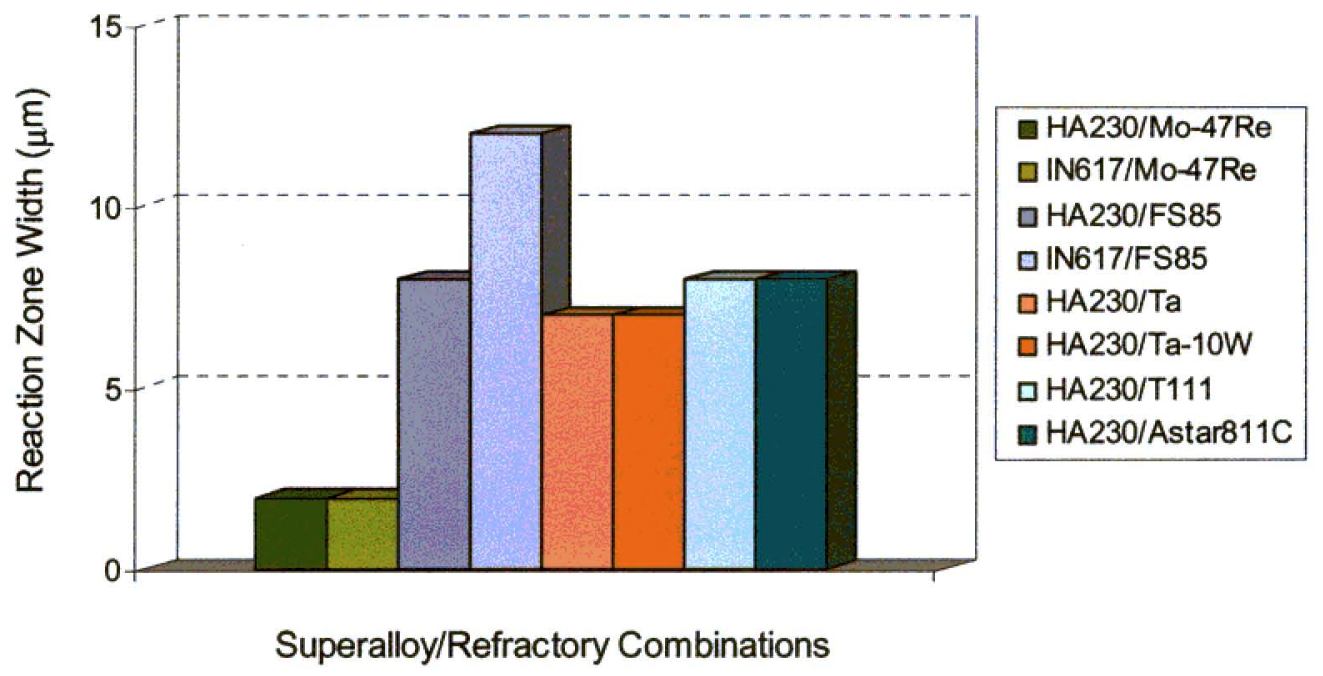

FIGURE 7. Interdiffusion Reaction Zone Width for the Ni-based Superalloy/Refractory Combinations Studied after a 4 Hour Hot Pressing at $1150 \mathrm{~K}$.

\section{Hot Pressing Versus Hot Isostatic Pressing}

The hot pressing techniques described in the previous section provide a convenient fabrication route for producing diffusion couples, but there was some concern that the reaction zone thickness and morphology might not be representative of reaction zones in prototypic components. Conversely, hot isostatic pressing (HIP), a different and more involved solid state joining technique, is a viable joining method for both coupons and large size components. Therefore a comparison was made between a refractory alloy and superalloy diffusion couple made by hot pressing and by hot isostatic pressing. In this regard, a panel of the HA230 was hot isostatic pressed to a Mo-47 Re panel at $1150 \mathrm{~K}$ for 1 hour with a pressure of $214 \mathrm{MPa}$ in argon. Figure 8 compares the reaction zone width for hot pressed and HIP'ped couples in the as fabricated condition and as a function of anneal times. The hot isostatic pressing process produced a good bond and an initial diffusion zone less than $1 \mu \mathrm{m}$. Because the hot pressing technique uses a lower pressure than hot isostatic pressing, a longer time is required during bonding step and the resulting reaction zone was notably thicker. Segments of the hot isostatic pressed diffusion couples were also annealed in argon for 100 and 300 hours at $1150 \mathrm{~K}$. Not surprisingly, the annealed HA230/Mo-47Re diffusion couples made by both techniques resulted in very similar microstructures and comparable diffusion zone thicknesses as illustrated in Figure 9 for 300 -hour annealed samples. These results provide confidence that the hot pressing technique can be used to screen the compatibility and diffusion reactions for the refractory/superalloy joints, and offer technical guidance to the material choices suitable to fabricate larger components.

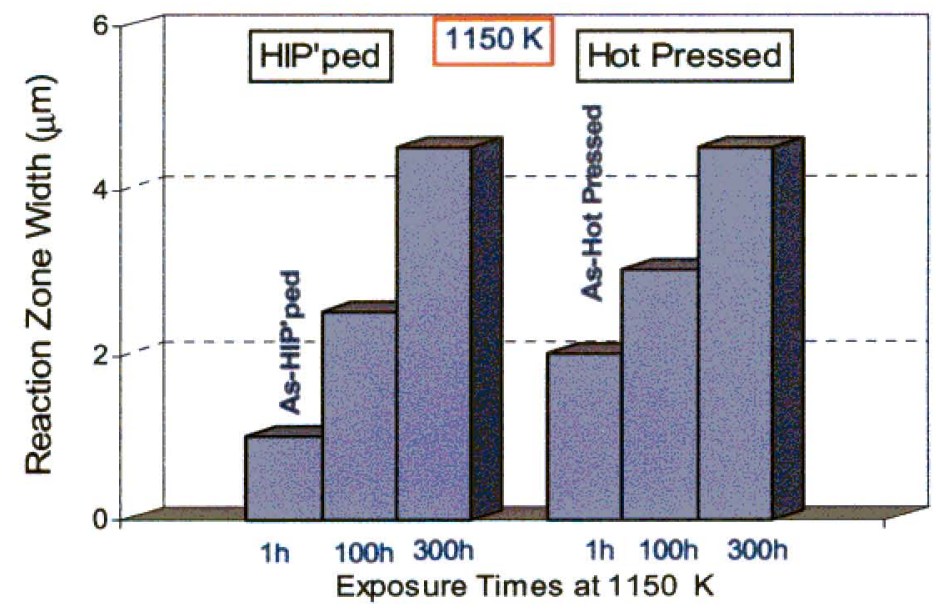

FIGURE 8. Interdiffusion Reaction Zone Width for HA230 Superalloy / Mo-47Re Refractory Bonded using Two Processing Techniques Followed by an Anneal Heat Treatment at $1150 \mathrm{~K}$ for 100 and 300 Hours. 


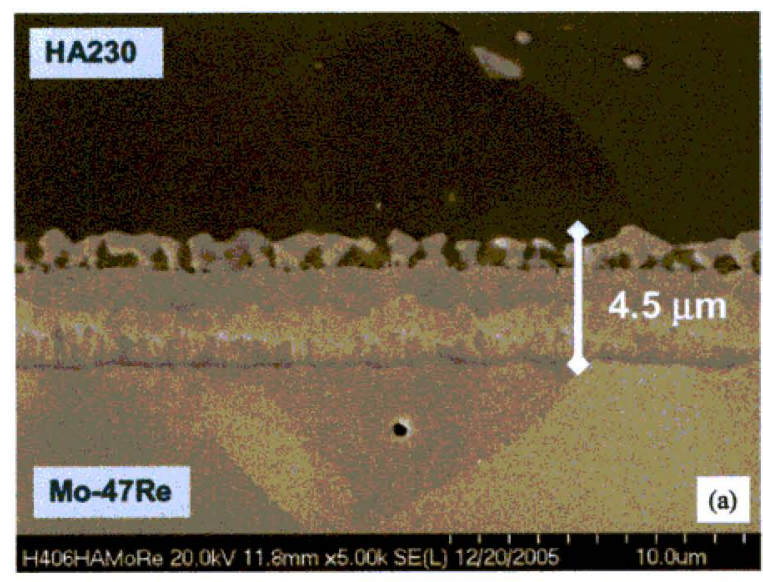

(a) Hot Pressed and Annealed

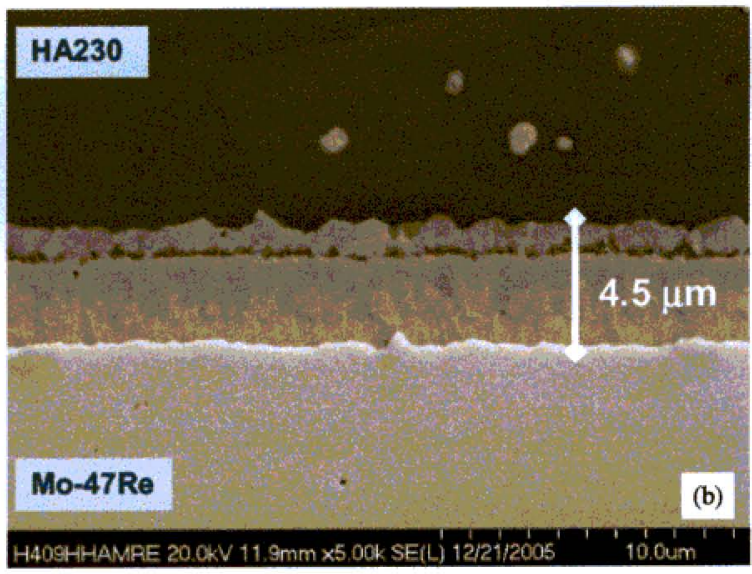

(b) HIP'ped and Annealed

FIGURE 9. FESEM Images Showing Similar Reaction Zone Widths after Bonding using Two Different Processing Techniques and Annealing at $1150 \mathrm{~K}$ for 300 Hours.

\section{Comparisons With Historical Data}

Figure 10 shows the growth rate of the reaction layer thickness as a function of temperature from the work of Buckman and Goodspeed (1969). They investigated Nb with both nickel and stainless steel alloys and found that the rate constant $(\mathrm{K})$, was high across their temperatures of interest. NASA GRC data for Nb alloy FS-85 is also superimposed on the plot and shows similarity to the Buckman and Goodspeed (1969) data for $\mathrm{Nb} / \mathrm{Ni}$-base couples. Reaction rates measured in this study for the Mo-47Re alloys are also superimposed on the figure and show that not only is the rate data significantly lower than the Nb-based FS-85 data measured in this study, but also lower than the data for Nb-based alloys coupled to a stainless steel alloy (321) and one Ni-base alloy (IN600) previously measured. Also of note, Buckman and Goodspeed (1969) observed lower diffusion rates in their Ta couples, along the lines of what could be expected for Mo-47Re at lower temperatures. Further study of Mo-47Re at lower temperatures as well as select couples that include a Ta alloy could be significant for identifying potentially viable dissimilar materials systems in future high-temperature power plant applications.

\section{CONCLUSIONS}

Solid-state bonding techniques provided sound bonds between nickel-based superalloys and various refractory metal alloys. No melting in the joint and minimal presence of potentially deleterious Kirkendall porosity was observed in the various diffusion couples studied. HIP and hot pressing techniques resulted in comparable diffusion zones after long term exposures, indicating that the hot pressing technique can be used to screen the compatibility and diffusion reactions for the refractory/superalloy joints. The Mo-47Re refractory alloy showed more promise - especially at temperatures of $1150 \mathrm{~K}$ or lower - than any other refractory alloy investigated. It appears that a single nickel-based alloy (e.g., Haynes $(230)$ could be used to establish practical joint temperatures for each class of refractory metal alloys as a function of proposed mission life.

\section{NOMENCLATURE}

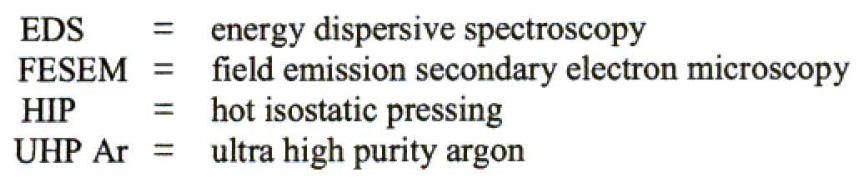




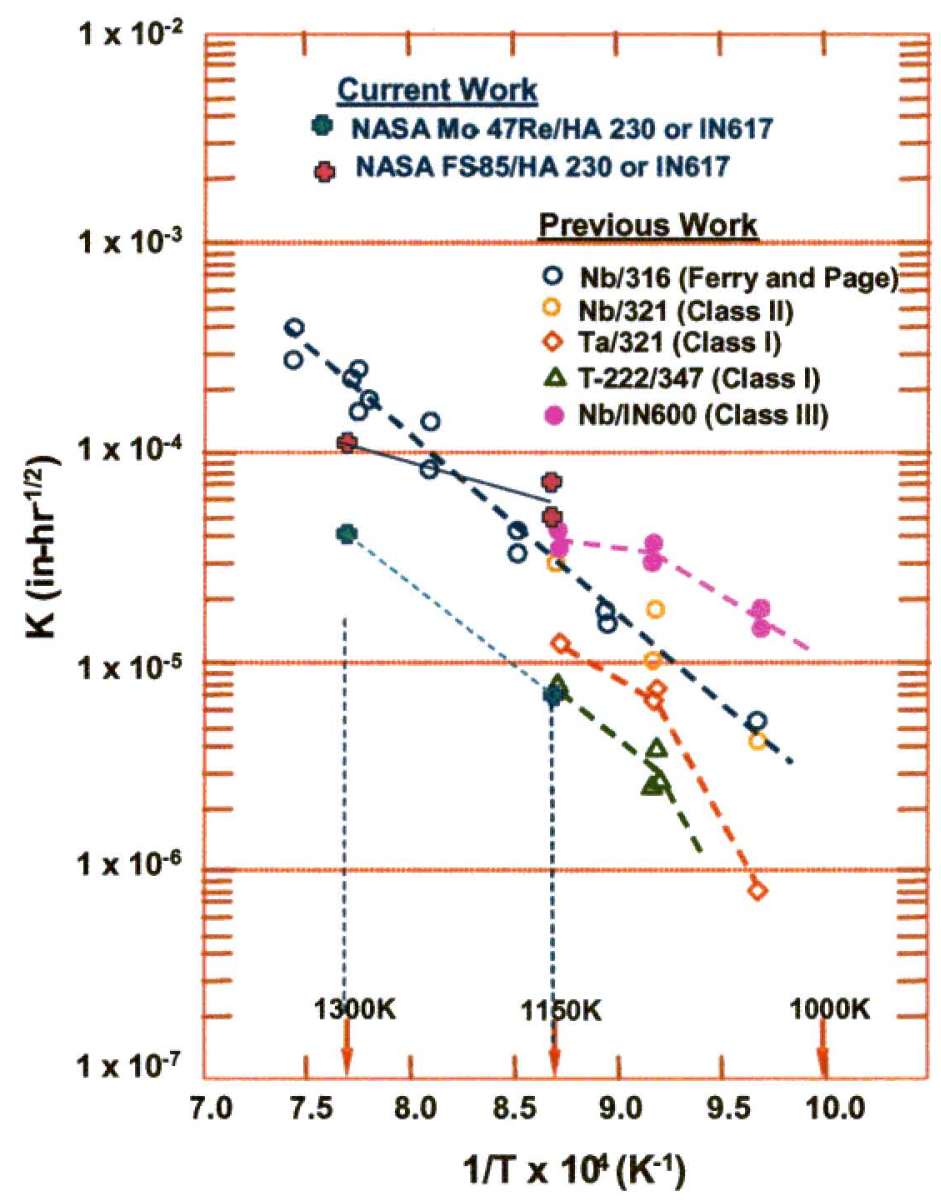

FIGURE 10. Parabolic Reaction Rate of Interdiffusion Zone Growth as a Function of Reciprocal Temperature for Various Ni-based Superalloy/Refractory or Austenitic Stainless Steel/Refractory Combinations.

\section{ACKNOWLEDGMENTS}

This research was supported through the Prometheus Power and Propulsion Program under NASA's Exploration Systems Mission Directorate. Any opinions expressed are those of the authors and do not necessarily reflect the views of NASA, the Department of Energy, or the Prometheus Program. The authors would like to acknowledge valuable discussions with T. Angeliu and R. W. Buckman. Excellent technical assistance from Donald Humphrey, John Juhas, Adrienne Veverka, Joy Buehler and Timothy Hawk is greatly appreciated.

\section{REFERENCES}

Buckman, R.W. and Goodspeed, R.C., "Evaluation of Refractory/Austenitic Bimetal Combinations," WANL-PR-(EE)-004, Westinghouse Astronuclear Laboratory, Pittsburg, PA, 1969.

Gould, J.E., et al., "Preliminary Investigations of Joining Technologies for Attaching Refractory Metals to Ni-base Superalloys," in the proceedings of Space Technology and Applications International Forum (STAIF-2006), edited by M.S. El-Genk, AIP Conference Proceedings No. 813, Melville, New York, 2006, pp. 757-765.

Mason, L.S., "A Power Conversion Concept for the Jupiter Icy Moons Orbiter," Journal of Propulsion and Power, 20, $902-910$, (2005).

Zinkle, S.J. and Wiffen, F.W., "Radiation Effects in Refractory Alloys," in the proceedings of Space Technology and Applications International Forum (STAIF-2004), edited by M.S. El-Genk, AIP Conference Proceedings No. 699, Melville, New York, 2004, pp. 733-740. 